\title{
Zij-instroom geneeskunde: wordt het kennisniveau van de reguliere studenten bereikt?
}

\author{
G.R. Terwisscha van Scheltinga, J. Schönrock-Adema, J.B.M. Kuks, M.F. van Driel, \\ J. Cohen-Schotanus
}

\section{Samenvatting}

Inleiding: Eén van de consequenties van de Bologna-verklaring en de invoering van de bachelor-masterstructuur in het hoger onderwijs is de mogelijkheid tot instroom in de medische master met een aanverwante bacheloropleiding. Door het dreigende artsentekort en de wens van de overheid om in verband hiermee sneller dan met vigerende curricula artsen op te leiden, werd hierop vooruitgelopen. Sinds 2002 wordt bij een aantal opleidingen geneeskunde de mogelijkheid geboden om in een hoger studiejaar in te stromen. Onderzocht werd of en zo ja wanneer de zij-instromers het kennisniveau bereiken van reguliere studenten geneeskunde. Tevens is nagegaan of er verschillen waren tussen zij-instromers met een afgeronde universitaire opleiding en zij-instromers met een afgeronde HBO-opleiding.

Materiaal en methoden: De proefgroep bestond uit 90 zij-instromers die in de jaren 2002-2004 het brugjaar geneeskunde aan de Rijksuniversiteit Groningen volgden. Om het kennisniveau van de studenten te meten, werd gebruik gemaakt van de longitudinale resultaten op de interfacultaire voortgangstoets, die vier maal per jaar wordt afgenomen. Middels t-toetsen werden verschillen geanalyseerd tussen zij-instromers en reguliere studenten en tussen zij-instromers met een afgeronde universitaire opleiding en zij-instromers met een afgeronde HBO-opleiding. Resultaten: Bij studieaanvang presteerden zij-instromers significant lager dan hun 'jaargenoten'. In de loop van het brugjaar verdwenen de verschillen. Er werden geen verschillen in prestaties gevonden tussen universitair opgeleiden en HBO-opgeleiden.

Discussie: Zij-instromers startten met een lager kennisniveau, maar scoorden binnen een jaar net zo goed als reguliere studenten. Zij-instroom in de masterfase, na een brugjaar, lijkt ook voor de studie geneeskunde een reële optie. (Terwisscha van Scheltinga GR, Schönrock-Adema J, Kuks JBM, Driel MF van, Cohen-Schotanus J. Zij-instroom geneeskunde: wordt het kennisniveau van de reguliere studenten bereikt? Tijdschrift voor Medisch Onderwijs 2006;25(4):164-169.)

\section{Inleiding}

In 1999 werd de Bologna-verklaring getekend door de onderwijsministers van de Europese Unie. De invoering van de bachelor-masterstructuur werd hiermee een feit. De bachelor-masterstructuur (BaMa) is een nadere uitwerking van afspraken die (inmiddels) 45 Europese landen hebben gemaakt. De invoering van de BaMa was ten eerste bedoeld om te komen tot onderling vergelijkbare graden in het hoger onderwijs. Een andere doelstelling van de Bologna-verklaring was dat studenten voortaan aan elke hogere Europese onder- wijsinstelling konden studeren. De nieuwe titels (bachelor en master) worden in heel Europa erkend en kunnen in elk Europees land behaald worden.

Ook voor de studie geneeskunde heeft de BaMa consequenties.1-3 Elke masteropleiding moet rechtstreeks toegankelijk zijn vanuit tenminste één academische bacheloropleiding. Daarnaast mag een master openstaan voor wetenschappelijke of professionele bachelors van andere opleidingen. In de meeste gevallen moet de student daarvoor eerst een schakelprogramma volgen, met als doel de student 
op het instapniveau van de gewenste masteropleiding te brengen.

Vooruitlopend op deze ontwikkelingen is het bij een aantal opleidingen geneeskunde in Nederland reeds mogelijk om te worden toegelaten tot de hogere studiejaren (zijinstroom) ${ }^{4}$ Directe aanleiding voor deze toelating was het dreigende artsentekort en de wens van de overheid om in verband hiermee sneller dan met de vigerende curricula artsen op te leiden. Voorwaarde voor zij-instroom is dat de student een (aanverwante) universitaire of HBO-opleiding heeft afgerond (bijvoorbeeld bewegingswetenschappen, farmacie of $\mathrm{HBO}-\mathrm{V}$ ) en voldoet aan de instroomeisen die ook aan de reguliere studenten worden gesteld (natuur- en scheikunde op VWO-niveau of het VWO-profiel 'Natuur en Gezondheid' of 'Natuur en Techniek'). Zij-instromers kunnen na een brugjaar in het vierde jaar van de reguliere opleiding instromen. Het doel van het brugjaar is het op peil brengen van het kennis- en vaardigheidsniveau van de studenten die in een latere fase van de studie geneeskunde instromen.

In dit onderzoek wordt ten eerste onderzocht of in het brugjaar het kennisniveau van de reguliere derdejaars studenten wordt gehaald. De aanname is dat de zij-instromers aanvankelijk een lacune in kennis bezitten en deze in een jaar weg kunnen werken. In de tweede plaats wordt nagegaan of zij-instromers met een vooropleiding op HBO-niveau verschillen qua kennisniveau van zij-instromers met een vooropleiding op WO-niveau.

\section{Materiaal en methoden}

\section{Proefpersonen en procedure}

Het onderzoek is uitgevoerd bij de opleiding geneeskunde aan de Rijksuniversiteit Groningen. De voortgangstoetsprestaties van zij-instromers die in 2002, 2003 en 2004 aan het brugjaar begonnen, zijn vergeleken met die van reguliere studenten die in diezelfde jaren in hun derde jaar instroomden. De zij-instromers werden geworven via een advertentie in diverse dagbladen. Voorwaarde voor toelating was een afgeronde, aan geneeskunde verwante $\mathrm{HBO}$ - of WO-opleiding en een VWO-getuigschrift met minimaal de vakken natuur- en scheikunde. De toelatingsprocedure bestond in 2002 uit een voortgangstoets, waarop het minimum niveau van een student geneeskunde bij de start van het derde jaar behaald moest worden, en een intakegesprek. Vanaf 2003 bestond de toelatingsprocedure uit drie toetsen: een algemene kennistoets met vragen over het gehele gebied van de klinische geneeskunde, een twintigtal vragen naar aanleiding van een artikel uit het Nederlands Tijdschrift voor Geneeskunde en een open-boek toets over enkele hoofdstukken uit het Textbook of Medical Physiology van Arthur C. Guyton. In 2002 werden 27 studenten tot het brugjaar toegelaten, in 200334 studenten en in 200432 studenten. De zij-instromers die het brugjaar met succes wisten te doorlopen, werden vervolgens toegelaten tot het (reguliere) vierde jaar van de opleiding geneeskunde.

Voor het onderzoek zijn de zij-instromers die na slechts één voortgangstoets te hebben gemaakt met het brugjaar stopten en de zij-instromers die tweemaal instroomden (bijvoorbeeld vanwege zwangerschap) buiten beschouwing gelaten. Dit resulteerde in de volgende samenstelling van de groepen zij-instromers. In 2002 bestond de groep zij-instromers uit 25 studenten met een gemiddelde leeftijd van 31,2 jaar. In 2003 bestond de groep uit 33 studenten met een gemiddelde leeftijd van 28,0 jaar. In 2004 bestond de groep uit 32 studenten met een gemiddelde leeftijd van 26,8 jaar (tabel 1).

\section{Brugjaar}

De basis voor de inhoud van het brugjaar was het reguliere derdejaars programma 
Tabel 1. Biografische gegevens zij-instromers 2002, 2003 en 2004.

\begin{tabular}{lccccccccc}
\hline Instroomjaar & $\mathbf{N}$ & \multicolumn{2}{c}{ Geslacht } & Vooropleiding & $\mathbf{M}$ & SD & Range \\
\hline & & vrouw & man & HBO & wO & leeftijd & & \\
\cline { 2 - 9 } 2002 & 25 & 5 & 20 & 13 & 12 & 31.2 & 7.24 & $21-44$ \\
2003 & 33 & 19 & 14 & 13 & 20 & 28.0 & 6.58 & $22-46$ \\
2004 & 32 & 16 & 16 & 7 & 25 & 26.8 & 5.09 & $22-39$ \\
\hline
\end{tabular}

van het toenmalige geneeskundecurriculum C2000. Hierin werden de eerste twee jaar gedomineerd door basisvakken in een klinische context, terwijl het derde jaar hoofdzakelijk uit klinische vakken in de context van basisconcepten bestond. Dit betekent dat de zij-instromers gedurende drie trimesters elke week vier uur in tutorgroepen werkten, vier uur vaardigheidsonderwijs volgden en colleges konden volgen. Daarnaast werden diverse capita selecta over leerstof uit de eerste twee studiejaren aangeboden. De onderwerpen van deze colleges hingen samen met de stof die gelijktijdig - maar dan vooral op klinisch niveau - in de derdejaars trimesters werd bestudeerd. Facultatief kon men deelnemen aan diverse practica uit het eerste en tweede studiejaar. De groepen werden wat betreft de vooropleiding van de zij-instromers zo divers mogelijk samengesteld, zodat de zij-instromers zoveel mogelijk van elkaar konden leren. De zij-instromers namen deel aan de reguliere derdejaars toetsen en legden bovendien een extra toets gericht op basisconcepten af aan het einde van ieder trimester. Al deze onderdelen moesten voldoende zijn om na het brugjaar in het vierde jaar te kunnen instromen.

\section{Voortgangstoets}

Om de zij-instromers te kunnen vergelijken met de reguliere studenten werd gebruik gemaakt van de resultaten die werden behaald op de voortgangstoets. De voortgangstoets is een schriftelijke kennistoets op het niveau van het artsexamen. De voortgangs- toets bestond ten tijde van het onderzoek uit 250 juist-onjuist vragen die volgens een vaste verdeling het gehele medische kennisdomein besloegen. ${ }^{5}$ Deze verdeling was in een blauwdruk vastgesteld door de medische faculteiten van Maastricht, Nijmegen en Groningen. ${ }^{6}$ Door dergelijke (in principe onderwijsonafhankelijke) toetsen regelmatig aan alle studenten voor te leggen, kan zicht worden verkregen op zowel de kennisgroei van jaarklassen als op de positie van individuen binnen de jaarklas. In een samenwerkingsverband tussen de genoemde faculteiten vindt de productie van vragen plaats. Alvorens vragen in de toets op te nemen, worden ze inhoudelijk en redactioneel beoordeeld door een vragenbeoordelingscommissie, in tegenstelling tot de reguliere tentamens.

De afname van de voortgangstoets vindt vier keer per jaar plaats. In alle drie genoemde plaatsen leggen alle studenten uit alle studiejaren gelijktijdig de toets af. Alle studenten, dus ook de zij-instromers, zijn verplicht deel te nemen. De normen voor de toets zijn in overleg met de zusterfaculteiten in Nijmegen en Maastricht vastgesteld.

Voor cohort 2002 zijn de derde-, vierdeen vijfdejaars resultaten op de voortgangstoets beschikbaar (toets 9 tot en met 20), van het cohort 2003 de derde- en vierdejaars resultaten (toets 9 tot en met 16) en van cohort 2004 de derdejaars resultaten (toets 9 tot en met 12). In dit onderzoek werd de gemiddelde score van de zij-instromers op de voortgangstoetsen vergeleken met die van de reguliere (Groningse) jaargenoten. 


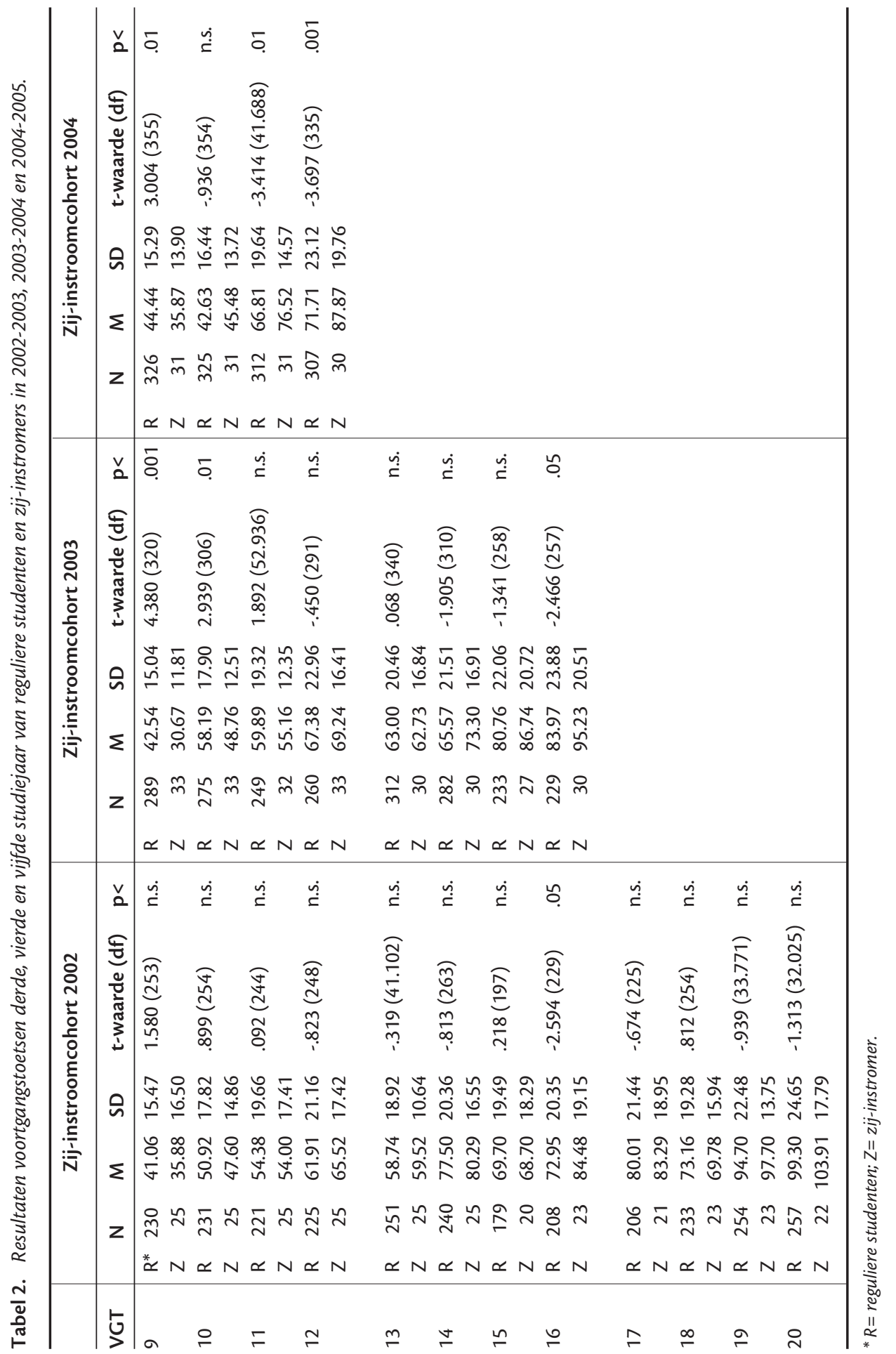




\section{Analyses}

Verschillen tussen de zij-instromers en de reguliere studenten en tussen zij-instromers met een HBO- en een WO-vooropleiding werden bepaald met t-toetsen.

\section{Resultaten}

In tabel 2 worden de resultaten op de voortgangstoetsen weergegeven. Uit de resultaten blijkt dat de zij-instromers aan het begin van het brugjaar lager scoorden dan de reguliere derdejaarsstudenten. Alle drie cohorten behaalden lagere scores op de eerste voortgangstoets (toets 9), waarbij de verschillen van cohort 2003 en 2004 significant waren. In 2003 behaalden ze ook op de tweede voortgangstoets significant lagere scores dan reguliere studenten. In alle drie cohorten haalden de zij-instromers de reguliere studenten in de loop van het brugjaar echter in qua kennisniveau: de verschillen werden per voortgangstoets kleiner. De prestaties op de derde en vierde voortgangstoets van het brugjaar van cohort 2004 waren significant hoger dan die van de reguliere studenten. Ook in de vervolgjaren scoorden de zij-instromers op de voortgangstoetsen telkens even hoog als of zelfs hoger dan reguliere studenten.

Uit analyses bleek verder dat er geen verschillen in prestaties op de voortgangstoetsen waren tussen zij-instromers met een vooropleiding op HBO-niveau en zij-instromers met een vooropleiding op WO-niveau.

\section{Discussie}

De hypothese in dit onderzoek was dat zij-instromers geneeskunde aanvankelijk minder goed presteren dan reguliere studenten geneeskunde, maar dat deze achterstand aan het eind van het brugjaar is verdwenen. De resultaten bevestigden deze hypothese. Op basis van deze bevinding kan worden geconcludeerd dat de doelen van het brugjaar, namelijk het wegwerken van eventuele achterstanden in de studie, in ieder geval wat betreft het kennisniveau, werden gehaald. Uit de resultaten is voorts gebleken dat er geen verschillen waren tussen studenten met een vooropleiding op WO- dan wel HBO-niveau. Blijkbaar is de studie geneeskunde goed te volgen in een korter en aangepast programma door studenten die een HBO- of universitaire (voor)opleiding hebben afgerond, voldoen aan de instroomeisen en door de selectieprocedure zijn gekomen. Het experiment met zij-instromers geneeskunde kan daarom als geslaagd worden beschouwd.

Uit de gegevens blijkt dat de gemiddelde leeftijd van de instromende groep een dalende tendens vertoont. Wij vermoeden dat de groep 'oudere' belangstellenden na de eerste twee rondes geminimaliseerd is. Onze verwachting is dan ook dat in de toekomst de meeste potentiële zij-instromers zich meteen na het afronden van een aanverwante bacheloropleiding zullen melden.

Dit onderzoek berust op de gegevens van de voortgangstoets. Het voordeel van deze gegevens boven reguliere toetsen is dat het een onderwijsonafhankelijke kennistoets is. Getoetst wordt of het vereiste kennisniveau wordt gehaald, waarover men in de betreffende fase van de opleiding zou moeten beschikken. Noch de reguliere studenten, noch de zij-instromers worden door deze toets bevoor- of benadeeld. Wij achten de voortgangstoets een geschikter instrument om het kennisniveau te meten dan de reguliere schriftelijke tentamens, omdat de laatste beïnvloed worden door ruis van het onderwijsprogramma. Daarbij is, door het gebruik van de toetsblauwdruk en de inzet van de vragenbeoordelingscommissies, de constructieprocedure van de voortgangstoets kwalitatief superieur.

Een beperking van dit onderzoek is dat de vergelijking tussen reguliere studenten geneeskunde en de zij-instromers werd beperkt tot het meten van het kennisniveau. De resultaten van het huidige 
onderzoek geven geen inzicht in de verdere competentieontwikkeling van de zijinstromers in de klinische fase. De zij-instromers hebben in het brugjaar hetzelfde vaardigheidsprogramma gevolgd als de reguliere studenten. Onze verwachting is dat ze zich ook wat betreft de examinering van de klinische competenties niet onderscheiden van de reguliere studenten. Of dat in de praktijk daadwerkelijk zo is, zou nader onderzocht moeten worden.

Op basis van dit onderzoek kan worden geconcludeerd dat het verantwoord is om de masterfase van het geneeskundecurriculum open te stellen voor studenten die een aanverwante bacheloropleiding hebben afgerond en die tevens voldoen aan de instroomeisen voor de studie geneeskunde.

\section{Literatuur}

1. Christensen L. The Bologna process and medical education. Med Teach 2004;26(7):625-9.

2. The Bologna declaration and medical education: a policy statement from the medical students of Europe. Med Teach 2005;27(1):83-5.

3. Breipohl W, Johansson C, Hansis M, Steiger J, Naguro T, Muller K, et al. Undergraduate medical education: tendencies and requirements in a rapidly developing Europe. Folia Medica 2000;42(2):5-16.
4. Lutke Schipholt I. In vier jaar basisarts: de lotgevallen van de zij-instromers (onderzoek). Med Contact 2004;59(51):2032-4.

5. Verhoeven BH. Progress testing: the utility of an assessment concept [dissertation]. Universiteit Maastricht. [s.l.: s.n.]; 2003.

6. Vleuten CPM van der, Schuwirth LWT, Muijtjens AMM, Thoben AJNM, Cohen-Schotanus J, Boven CPA van. Cross institutional collaboration in assessment: a case on progress testing. Med Teach 2004;26(8):719-25.

De auteurs:

Drs. G.R. Terwisscha van Scheltinga is studieadviseur en coördinator zij-instroom.

Mw. dr. J. Schönrock-Adema is medewerker van het Centrum Onderzoek en Innovatie Medisch Onderwijs.

Prof. dr. J.B.M. Kuks is neuroloog en curriculumcoordinator.

Dr. M.F. van Driel is uroloog en docent zij-instroom. Mw. dr. J. Cohen-Schotanus is hoofd Onderzoek en Innovatie Medisch Onderwijs.

Allen zijn verbonden aan de Faculteit der Medische Wetenschappen, Universitair Medisch Centrum Groningen.

Correspondentieadres:

Drs. G.R. Terwisscha van Scheltinga, Onderwijsinstituut FMW/UMCG, A. Deusinglaan 1, 9713 AV Groningen, tel.: 050-3638355, g.r.terwisscha.van.scheltinga@ med.umcg.nl.

Belangenconflict: geen gemeld.

Financiële ondersteuning: geen gemeld.

\section{Summary}

Introduction: The Bologna Declaration and the bachelor-master structure make it possible to offer graduate entry programmes in medicine to students with degrees in subjects related to medicine, such as pharmacology, physiotherapy, nursing and medical biology. University Medical Center Groningen allows these students to enter year four of the regular programme after a transitional year, the so-called ZIG year, which was first offered in 2002. We examined whether: 1) there were differences in knowledge between graduate entry students with university degrees and degrees from schools for higher vocational education and 2) whether (and when) the graduate entry students' knowledge reached a comparable level to that of the regular medical students.

Material and methods: We compared progress test results of ninety graduate entry students who followed the transitional year between 2002 and 2004 with those of the regular students. In the transitional year the comparison was with students in year 3. At University Medical Center Groningen, all medical students sit four progress tests every year. T-tests were performed to examine for differences between the two groups and within the graduate entry group.

Results: Initially, the graduate entry students scored significantly lower, but the difference disappeared within a year. No differences were found within the graduate entry group.

Discussion: After initial lower knowledge levels the graduate entry students caught up with the regular students quite quickly. The conclusion seems justified that after a transitional year graduate entry students with degrees in subjects related to medicine are ready to enter the medical undergraduate programme. (Terwisscha van Scheltinga GR, Schönrock-Adema J, Kuks JBM, Van Driel MF, Cohen-Schotanus J. Graduate entry programme in medicine: do students reach the same knowledge level as the students in the regular programme? Dutch Journal of Medical Education 2006;25(4):164-169.) 